\title{
Oral health-related quality of life: acrylic versus flexible partial dentures
}

\author{
Clara A. Akinyamoju ${ }^{1}$, Oluwole O. Dosumu ${ }^{2}$, Juliana O. Taiwo ${ }^{3}$, Tunde J. Ogunrinde ${ }^{2}$ and Akindayo \\ O. Akinyamoju ${ }^{4}$
}

Ghana Med J 2019; 53(2): 163-169 doi: http://dx.doi.org/10.4314/gmj.v53i2.12

\author{
${ }^{1}$ Department of Family Dentistry, University College Hospital, Ibadan, Nigeria \\ ${ }^{2}$ Department of Restorative Dentistry, University of Ibadan/ University College Hospital, Ibadan Nigeria \\ ${ }^{3}$ Department of Periodontology and Community Dentistry, University of Ibadan/ University College Hospital, \\ Ibadan, Nigeria \\ ${ }^{4}$ Department of Oral Pathology, University of Ibadan/ University College Hospital, Ibadan, Nigeria
}

Corresponding author: Clara Arianta Akinyamoju

Conflict of interest: None declared

E-mail: arianta11@yahoo.com

\section{SUMMARY}

Background: Teeth lost are usually replaced by all-acrylic removable partial dentures (RPD) because of its affordability and ease of fabrication. The all-acrylic RPD is said to cause significant periodontal injury and consequently affect the oral health related quality of life (OHRQoL) of denture wearers.

Objective: To determine and compare OHRQoL of all-acrylic and flexible RPD wearers at baseline and after use of dentures.

Design and setting: Study was quasi-experimental using a cross-over design, involving 30 patients with Kennedy class IV and anterior class III arches. Patient recruitment and review were done over an eight-month period in the Prosthetic Unit of a tertiary health facility. OHRQoL was assessed with the oral health impact profile-14 questionnaire. Data were analysed using descriptive and multivariate analysis at asignificant level of $\mathrm{p}<.05$.

Results: Mean age of patients was $33.8 \pm 10.0$ years; at baseline, patient reported occasionally, fairly often or very often for 11(78.6\%) OHIP items. However, after using the acrylic and flexible partial dentures, 11(36.6\%) patients reported having trouble pronouncing words and $9(30.0 \%)$ found it uncomfortable to eat respectively. At baseline, there was a difference in mean OHIP scores with age $(\mathrm{p}=.02)$; scores reduced from $12.4 \pm 9.8$ to $4.8 \pm 5.3$ (CI=3.3$12.0, \mathrm{p}=.001)$ after using the all-acrylic denture and 3.8 $\pm 5.6(\mathrm{CI}=4.3-13.0, \mathrm{p}<.001)$ with the flexible denture.

Conclusion: There was improvement in the OHRQoL of patients with use of flexible partial dentures. Therefore, thermoplastic materials are possible alternative RPD base materials in patient management.

Keywords: OHIP-14, Removable partial dentures, Quality of Life, acrylic dentures, flexible dentures Funding: None declared

\section{INTRODUCTION}

Tooth loss has been attributed to several causes including trauma, caries, periodontal disease and other oral pathologies. It affects an individual's psychological health and also distorts aesthetics, phonetics, and functional occlusion. ${ }^{1}$ Modern dentistry offers many options for the restoration of partial edentulous mouths, including removable partial dentures (RPDs), fixed bridges and dental implants. RPDs are viable methods for replacing missing natural teeth. ${ }^{2}$ Benefits of restoring missing teeth include the prevention of pathological drifting of adjacent teeth as well as the supra-eruption of opposing teeth. Other benefits include reduction of occlusal loading on the remaining natural teeth and the enhancement of oral function and comfort. ${ }^{2}$
Traditionally, cast metal is used for fabrication of dentures while polymethyl methacrylate has also been used when facilities for cast metal dentures are unavailable or due to the lower cost of acrylic. ${ }^{3}$ Its advantages include satisfactory aesthetic property and clearly defined processing method in dental application. However, it has the disadvantage of poor mechanical property, difficulty with insertion in undercut areas, brittleness which leads to fracture and allergy to methyl methacrylate monomer. ${ }^{4,5}$

Despite these challenges, they are the most commonly used prostheses in replacing missing teeth in developing countries; this is because they are cheaper and easier to fabricate. ${ }^{3}$ 
The popular use of acrylic RPD has resulted in several attempts to improve its usability and overcome some of its limitations. The introduction of the nylon-derived denture base material paved the way for a new type of denture and has been seen as advancement in dental material science. ${ }^{6}$ This material replaces the metallic and the pink acrylic denture framework for cast metal RPDs, it is used to make prosthesis commonly referred to as flexible prosthesis. They provide exceptional aesthetics and comfort, a well-executed flexible prosthesis can provide years of service for the RPD wearer. ${ }^{6,7}$ Therefore, flexible RPDs can greatly reduce the need for the expensive cast metal frameworks. ${ }^{8}$ In addition, the type of major connector used for denture construction may influence the level of patients' satisfaction and thus quality of life. ${ }^{9}$ Also, when considering the outcome of prosthodontic treatment, success is often judged differently by dentists and patients; though the patient's well-being is always the main aim of the treatment approach adopted by the dentist. ${ }^{10}$

Clinical practice utilizes predetermined criteria for assessing treatment outcomes. Often times, these criteria do not take into account the requirements and attitude of individual patients. ${ }^{11}$ Thus, it is necessary to assess a patient's daily experience of disease and treatment on physical, psycho-social and social functions otherwise known as the health-related quality of life. Oral health related quality of life (OHRQoL) has been defined as a multidimensional construct that reflects (among other things) people's comfort when eating, sleeping, and engaging in social interaction; their self-esteem; and their satisfaction with respect to their oral health. ${ }^{12}$ Therefore, the purpose of this study was to assess the quality of life of RPD wearers with respect to acrylic and flexible dentures, to provide a broader appreciation of the impact of dentures on oral health.

The study was based on the hypotheses that:

(a) The base material of RPDs has an effect on patients' OHRQoL.

(b) The OHRQoL of an individual using an RPD is influenced by age and gender.

\section{METHODS}

The study design was quasi-experimental using a crossover treatment design. Ethical approval was obtained from the University of Ibadan/ University College Hospital ethical review board (UI/EC/14/0005). Thirty consecutive patients requiring RPDs were selected from the Prosthetics Clinic, University College Hospital, Ibadan. Sample size calculation was done using the formula for comparison of paired means at a power of $90 \%$ based on OHIP scores of patients using two types of RPDs. ${ }^{13}$

Patient recruitment and follow-up were done over an eight-month period. Patients included in the study were aged 16 years or more, having one to three missing teeth in the anterior region of either the maxillary or mandibular arch (Kennedy class IV and anterior class III edentulous spaces) for a period of three months or more. As well as, those with mild to moderate Seibert's classes I and II edentulous ridge. ${ }^{14}$ Individuals with a history of denture use, those with Kennedy class I, II, and posterior class III edentulous spaces and patients with any signs of periodontal disease e.g. pain/ pus discharge/mobility of abutment teeth were excluded from the study. The purpose and procedure for the study were explained to all participants and written informed consent was taken from the patients prior to inclusion in the study.

\section{Data collection instruments}

An interviewer-administered, semi-structured questionnaire was used to obtain socio-demographic data such as age, sex, occupation and level of education. ${ }^{15}$ The participants were categorized into upper, upper middle, lower middle and lower social classes using a standard occupational classification system. ${ }^{16}$ The OHRQoL was assessed with the OHIP-14 questionnaire; this questionnaire has been validated amongst Nigerians requiring dental treatment and was seen to have good psychometric properties. ${ }^{17}$ The questionnaire has 14 items of impact, which are conceptually divided into seven domains: functional limitation, pain, psychological discomfort, physical disability, psychological disability, social disability and handicap. Each domain comprising two items of impact such as speaking clearly, sense of taste,pain, uncomfortable eating, self-consciousness, tension, unsatisfactory diet, interrupted meals, difficulty in relaxing, being embarrassed, being irritable with others, occupational role, unsatisfactory life and inability to function.

Each item of impact was assessed using a likert-type scale with five options: never (score 0) "hardly ever" (score 1), "occasionally" (score 2), "fairly often" (score 3) and "very often", (score 4). The OHIP-14 outcome varies from 0 to 56 , the higher the summary score the higher the level of impact on oral well-being and quality of life. The simple count method in which the total impact score is calculated by summing the number of OHIP items responded to as very often, fairly often and occasionally, was used for the baseline and after use of appliance scores; the total impact score was also calculated by adding up the individual scores recorded for the 14 items (additive method). The percentage of individuals responding 'occasionally', 'fairly often' or 'very often' on an item was reported as prevalence of impact on OHRQoL while the number of items recorded as occasionally, fairly often and very often were reported as extent of impact on OHRQoL. 
The total OHIP-14 item scores comprising all levels of response made up measure of severity of adverse impacts caused by oral conditions at baseline and with dentures, this was categorized into none (0-4), little (5-9), moderate (10-14), great (15-19) and extreme $(\geq 20) .{ }^{18}$

Pretesting of the OHIP-14 and semi-structured questionnaire for obtaining socio-demographic variables were done on five patients requiring RPDs who were not part of the study. Questions on difficulty in understanding OHIP items/ dimensions were asked in order to improve the ease of administering the instrument. Intra-examiner calibration was done based on repeat administration of the questionnaires. The OHIP-14 and the questionnaire for obtaining data on socio-demographics were administered through face to face interviews by a single interviewer at baseline and at one month interval after use of the acrylic and flexible partial dentures.

\section{Clinical and laboratory procedures}

Participants were examined on a dental chair using gloves, sterile mouth mirror and a Community Periodontal Index probe (CPI probe), subsequently, patients were randomly allocated into two groups using ballot papers. The ballot papers were coded 1 for acrylic and 2 for flexible dentures; participants who picked ballot paper 1 were allocated to Group 1 and were given an acrylic RPD at initial presentation while those who picked ballot paper 2 were allocated to Group 2 and started with the flexible RPD. Thereafter, impressions of participants' maxillary and mandibular arches were taken in sterile well-fitting stock trays with irreversible hydrocolloid impression material. The cast was poured immediately with type III dental stone and duplicated with reversible hydrocolloid to produce two working casts for the acrylic and flexible dentures to ensure an exact dimension for both dentures. Tooth shade was selected, and the teeth selected for the two dentures were of the same brand, shade, size and shape. To standardize the arrangement of the teeth for the dentures, an over-impression of the teeth on the working cast of the initial denture was made using putty impression material, which was used to locate the exact position of the teeth on the second denture. Clasps made with valplast and wrought wire for the flexible and acrylic dentures respectively were incorporated in the dentures when necessary. A try-in of the trial denture was done for both dentures; Valplast (Dentiflex- Roko, Poland) was used for the fabrication of the flexible dentures by injection moulding technique and acrylic resin (Trevalon $^{\mathrm{R}}$ ) for the acrylic dentures by compression moulding.

All laboratory procedures were carried out by one dental technologist; 60 (30 flexible and 30 acrylic) dentures were fabricated.
Scale and polish was done for all participants before fitting the dentures. Post insertion instructions were given to the patients in oral and written forms.

The participants were given review appointments at 24 hours, one week and one month and were reminded of their review appointments through text messages and telephone calls. At the 24 hour and one week reviews, concerns with the dentures were addressed and necessary adjustments made on the dentures. While at the one month review, the OHIP-14 questionnaire was administered.

Participants were reviewed by one of the authors. The one month period was considered sufficient to make informed and objective judgment about the dentures. ${ }^{13} \mathrm{Ap}-$ propriate infection control protocol was followed using primary barrier method with adequate disposable materials. The study was self funded.

\section{Data management}

The data were analyzed with the Statistical Package for Social Sciences (SPSS Inc. Chicago IL) version 19. The difference in mean OHIP scores was tested with paired ttest, student $t$ test to test association between OHIP-14 item scores and sex. The association between OHIP-14 scores, age and social class was tested with Analysis of variance (ANOVA). The level of significance was set at $\mathrm{p}<0.05$.

\section{RESULTS}

Table 1 Frequency distribution of the participants by socio-demographic characteristics

\begin{tabular}{|l|l|}
\hline Socio-demographic characteristics & N $(\%)$ \\
\hline Age group (years) & \\
\hline $16-25$ & $9(30)$ \\
\hline $26-35$ & $7(23.3)$ \\
\hline $36-45$ & $11(36.7)$ \\
\hline $46-55$ & $3(10)$ \\
\hline Sex & \\
\hline Male & $15(50)$ \\
\hline Female & $15(50)$ \\
\hline Marital status & \\
\hline Single & $13(43.3)$ \\
\hline Married & $17(56.7)$ \\
\hline Social class & \\
\hline Upper middle class & $3(10)$ \\
\hline Lower middle class & $9(30)$ \\
\hline Lower class & $18(60)$ \\
\hline Educational status & \\
\hline Primary school & $2(6.7)$ \\
\hline Secondary school & $10(33.3)$ \\
\hline Post-secondary (technical college) & $5(16.7)$ \\
\hline Tertiary & $13(43.3)$ \\
\hline
\end{tabular}

The mean age of the 30 participants in the study was $33.8 \pm 10.0$ years. Other characteristics of the participants are shown in Table 1. 


\section{Original Article}

At baseline, participants reported occasionally, fairly often or very often for $11(78.6 \%)$ OHIP items. Majority $(76.7 \%)$ reported impact in the item 'being self-conscious because of problems with the mouth', followed by $16(53.3 \%)$ participants who gave account of being embarrassed because of problems with their mouth.

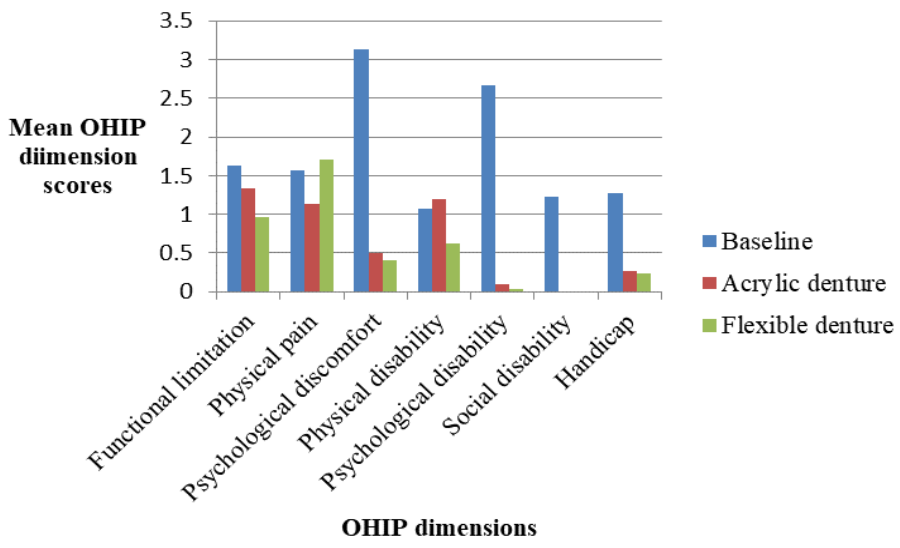

Figure 1 Mean OHIP dimension scores at baseline, with acrylic and flexible partial dentures
Also, $14(46.7 \%)$ of them reported having trouble pronouncing words and 10(33.3\%) indicated impact for these respective items: interruption of meals, irritability with people, life was generally less satisfying (Table 2).

Furthermore, 7(23.3\%) reported scores indicating extreme impact of oral conditions on OHRQoL. The OHIP dimension with the highest mean score was psychological discomfort (Figure 1). However, after use of the acrylic partial denture, participants experienced impact on six (6) OHIP items. Eleven (40.0\%) participants reported having trouble pronouncing words, $9(30.0 \%)$ said they found it uncomfortable to eat and $8(26.7 \%)$ interrupted meals because of problems with the denture. No participant experienced impact on the items- embarrassed because of problems with the denture, being irritable with other people, difficulty doing job and being totally unable to function. Likewise, participants reported no impact for these same OHIP items after use of the flexible partial denture. On the other hand, they stated impact in five (5) items, $9(30.0 \%)$ participants said they felt uncomfortable while eating, $4(13.3 \%)$ had to interrupt meals and $4(13.3 \%)$ indicated having painful aching in their mouth with use of the flexible denture (Table 2).

Table 2 Impact on OHRQOL of participants at baseline, with acrylic and flexible dentures

\begin{tabular}{|c|c|c|c|}
\hline Item & Baselinen $(\%)$ & Acrylic $n(\%)$ & Flexible $n(\%)$ \\
\hline \multicolumn{4}{|c|}{$\begin{array}{l}\text { Prevalence of impact(people reporting one or more OHIP items occasionally, fairly } \\
\text { often or very often) }\end{array}$} \\
\hline \multicolumn{4}{|l|}{ Function limitation } \\
\hline Trouble pronouncing words & $14(46.7)$ & $11(36.6)$ & $6(20.0)$ \\
\hline Worsened sense of taste & $3(10.0)$ & $3(10.0)$ & $2(6.7)$ \\
\hline \multicolumn{4}{|l|}{ Physical pain } \\
\hline Painful aching in the mouth & $9(30.0)$ & $2(6.7)$ & $4(13.3)$ \\
\hline Found it uncomfortable to eat & $8(26.7)$ & $9(30.0)$ & $9(30.0)$ \\
\hline \multicolumn{4}{|l|}{ Psychological discomfort } \\
\hline Self-conscious & $23(76.7)$ & $6(20.0)$ & $1(3.3)$ \\
\hline Felt tense & $7(23.3)$ & $1(3.3)$ & $2(6.7)$ \\
\hline \multicolumn{4}{|l|}{ Physical disability } \\
\hline Unsatisfactory diet & $4(13.3)$ & $4(13.3)$ & $1(3.3)$ \\
\hline Interruption of meals & $10(33.3)$ & $8(26.7)$ & $4(13.3)$ \\
\hline \multicolumn{4}{|l|}{ Psychological disability } \\
\hline Difficulty to relax & $10(33.3)$ & $1(3.3)$ & - \\
\hline Embarrassed & $16(53.3)$ & - & - \\
\hline \multicolumn{4}{|l|}{ Social disability } \\
\hline Bit irritable with other people & $10(33.3)$ & - & - \\
\hline Difficulty doing your job & $3(10.0)$ & - & - \\
\hline \multicolumn{4}{|l|}{ Handicap } \\
\hline Felt life was generally less satisfying & $10(33.3)$ & $1(3.3)$ & - \\
\hline Totally unable to function & $4(13.3)$ & - & - \\
\hline \multicolumn{4}{|c|}{ Extent of impact (number of items reported occasionally, fairly often, very often) } \\
\hline Number of items with no impact & $3(21.4)$ & $8(57.1)$ & $9(64.3)$ \\
\hline Number of items with impact & $11(78.6)$ & $6(42.9)$ & $5(35.7)$ \\
\hline \multicolumn{4}{|l|}{ Severity of impact (sum of ordinal responses) } \\
\hline None $(0-4)$ & $9(30.0)$ & $17(56.7)$ & $22(73.3)$ \\
\hline Little (5-9) & $5(16.7)$ & $7(23.3)$ & $3(10.0)$ \\
\hline Moderate (10-14) & $4(13.3)$ & $5(16.7)$ & $3(10.0)$ \\
\hline Great (15-19) & $5(16.7)$ & $1(3.3)$ & $2(6.7)$ \\
\hline Extreme $(\geq 20)$ & $7(23.3)$ & - & - \\
\hline Summary mean OHIP score & $12.4 \pm 9.8$ & $4.8 \pm 5.3$ & $3.8 \pm 5.6$ \\
\hline
\end{tabular}




\section{Original Article}

Table 3 Comparing mean OHIP dimension/ item scores of participants at baseline with acrylic and flexible denture use

\begin{tabular}{|c|c|c|c|c|c|c|}
\hline \multirow[t]{3}{*}{ OHIP Dimension/ Items } & \multicolumn{3}{|l|}{ Acrylic } & \multicolumn{3}{|l|}{ Flexible } \\
\hline & Mean & & & Mean & & \\
\hline & Difference (SD) & $\mathrm{Cl}$ & $\mathrm{p}$ value & Difference (SD) & $\mathrm{Cl}$ & $\mathrm{p}$ value \\
\hline Function Limitation & $0.3(2.4)$ & $-0.6-1.2$ & .49 & $0.7(2.6)$ & $-0.3-1.6$ & .16 \\
\hline Worsened sense of taste & $-0.1(1.2)$ & $-0.6-0.3$ & .54 & $-0.1(1.2)$ & $-0.5-0.4$ & .77 \\
\hline Physical Pain & $0.4(2.9)$ & $-0.6-1.5$ & .42 & $-0.1(3.3)$ & $-1.4-1.1$ & 83 \\
\hline Painful aching in the mouth & $0.5(1.3)$ & $0.0-1.0$ & .04 & $0.1(1.4)$ & $-0.4-0.6$ & .69 \\
\hline Psychological Discomfort & $2.6(2.7)$ & $1.6-3.6$ & $<.001$ & $2.7(2.5)$ & $1.8-3.7$ & $<.001$ \\
\hline Self conscious because of dentures & $1.9(1.8)$ & $1.2-2.6$ & $<.001$ & $2.2(1.6)$ & $1.6-2.8$ & $<.001$ \\
\hline $\begin{array}{l}\text { Felt tense because of problems with den- } \\
\text { tures }\end{array}$ & $0.6(1.4)$ & $0.1-1.2$ & .02 & $0.5(1.4)$ & $-0.0-1.0$ & .06 \\
\hline Physical Disability & $-0.1(2.3)$ & $-1.0-0.7$ & .76 & $0.4(1.9)$ & $-0.3-1.1$ & .22 \\
\hline Unsatisfactory diet with dentures & $-0.1(1.5)$ & $-0.6-0.5$ & .81 & $-0.1(1.4)$ & $-0.7-0.4$ & .61 \\
\hline Interruption of meals with dentures & $-0.1(1.5)$ & $-0.6-0.5$ & .81 & $0.2(1.2)$ & $-0.3-0.7$ & .39 \\
\hline Psychological Disability & $2.6(2.6)$ & $0.6-3.5$ & $<.001$ & $2.6(2.6)$ & $1.7-3.6$ & $<.001$ \\
\hline $\begin{array}{l}\text { Embarrassed because of problems with } \\
\text { dentures }\end{array}$ & $1.5(1.6)$ & $1.0-2.1$ & $<.001$ & $1.5(1.6)$ & $0.9-2.1$ & .001 \\
\hline Social Disability & $1.2(1.7)$ & $1.9-4.1$ & $<.001$ & $1.2(1.7)$ & $0.6-1.9$ & $<.001$ \\
\hline Bit irritable with other people & $1.0(1.4)$ & $0.4-1.5$ & .001 & $1.0(1.4)$ & $0.4-1.5$ & .001 \\
\hline Difficulty doing your job & $0.3(0.8)$ & $-0.0-0.6$ & .09 & $0.3(0.8)$ & $-0.0-0.6$ & .08 \\
\hline Handicap & $1.0(1.8)$ & $0.3-1.7$ & .005 & $1.0(2.1)$ & $0.3-1.8$ & .01 \\
\hline Felt life was generally less satisfying & $0.6(1.8)$ & $0.1-1.1$ & .02 & $0.7(1.7)$ & $0.0-1.3$ & .04 \\
\hline Totally unable to function & $0.4(1.0)$ & $-0.0-0.7$ & .05 & $0.4(1.0)$ & $-0.0-0.7$ & .05 \\
\hline Summary OHIP Score & $7.7(11.6)$ & $3.3-12.0$ & .001 & $8.6(11.7)$ & $4.3-13.0$ & $<.001$ \\
\hline
\end{tabular}

The dimension with the highest mean OHIP score after using the acrylic and flexible dentures were physical disability and physical pain respectively as seen in Figure 1. Additionally, at baseline, there was a difference in the mean OHIP scores of the participants with age $(\mathrm{p}=.02)$, with highest mean OHIP score recorded for those aged 26-35 years. Individuals in the lower social class (14.6 \pm 9.4$)$ and females (13.8 \pm 0.9$)$ had the highest mean OHIP scores, though not statistically significant (Table 4). There was progressive decline in the mean OHIP scores from baseline, after use of acrylic denture and flexible partial dentures for all age groups. When comparing the mean OHIP dimension/item scores reported by participants after using both types of dentures with that reported at baseline, the mean differences observed for the dimension of psychological discomfort with its related items were significant for both types of dentures ( $p<$ .001). Furthermore, there was a considerable mean difference between baseline OHIP scores and after use of acrylic and flexible partial dentures for the OHIP dimensions/ items of psychological disability, social disability and handicap $(\mathrm{p}<.05)$ (Table 4).

\section{DISCUSSION}

The absence of teeth may cause functional impairment, affecting a person's chewing and aesthetics depending on the location of the missing tooth/teeth, with subsequent impact on quality of life. ${ }^{19}$
Table 4 Mean OHIP item scores of participants at baseline with acrylic and flexible partial dentures by age, social class and sex

\begin{tabular}{|c|c|c|c|}
\hline & Baseline & Acrylic & Flexible \\
\hline & Mean (SD) & Mean (SD) & Mean (SD) \\
\hline \multicolumn{4}{|l|}{ Age Group (years) } \\
\hline $16-25$ & $14.6(8.0)$ & $6.4(4.9)$ & $4.0(7.0)$ \\
\hline $26-35$ & $20.4(10.9)$ & $3.9(6.6)$ & $3.6(5.1)$ \\
\hline $36-45$ & $7.5(7.9)$ & $4.0(4.8)$ & $3.7(5.9)$ \\
\hline $46-55$ & $5.7(4.7)$ & $4.7(6.4)$ & $4.3(1.5)$ \\
\hline p-value & 0.02 & 0.74 & 0.99 \\
\hline \multicolumn{4}{|l|}{ Social Class } \\
\hline Upper middle & $6.0(5.3)$ & $9.0(6.1)$ & $3.7(2.1)$ \\
\hline Lower middle & $10.2(10.9)$ & $2.7(3.8)$ & $6.1(7.8)$ \\
\hline Lower & $14.6(9.4)$ & $5.1(5.5)$ & $2.7(4.5)$ \\
\hline p-value & 0.28 & 0.18 & 0.34 \\
\hline \multicolumn{4}{|l|}{ Sex } \\
\hline Female & $13.8(10.9)$ & $4.1(4.9)$ & $4.5(5.9)$ \\
\hline Male & $11.1(8.7)$ & $5.4(5.6)$ & $3.1(5.3)$ \\
\hline p-value & 0.46 & 0.52 & 0.5 \\
\hline
\end{tabular}

The participants presenting for RPDs in this study were similar to those in other Nigerian studies in which majority were adults aged 17-40 years. ${ }^{20,21}$ Younger adults more often request for dentures replacing missing anterior teeth, unlike older individuals who ask for prostheses to replace other classes of edentulousness. ${ }^{22}$ 
The reason may be that in this environment, younger adults are at higher risk of losing their anterior teeth on account of trauma, unlike older persons who lose their teeth primarily on account of periodontal disease. ${ }^{23}$

The mean baseline OHIP score (12.4 \pm 9.8$)$ of the patients in this study was comparable to that reported by other individuals requiring dental prostheses. ${ }^{13,17}$ But was slightly lower than that reported by Papagiannopoulou et al., 14.9 $10.0 .{ }^{24}$ The OHIP item for which most patients in this study stated impact at baseline differed from that of studies by Murariu and Hanganu, as well as Lawal et al., who stated more impact in the items 'interruption of meals' (56\%) and 'painful aching in the mouth' (69.1\%) respectively. ${ }^{17,25}$ The individuals involved in this study had missing anterior teeth, which may account for the high prevalence of impact in the item 'feeling self-conscious', as missing anterior teeth have been associated with higher impact on OHRQoL. ${ }^{26}$ On the contrary, Motallebnejadet al., while validating the Persian version of the OHIP-14 among patients requiring dental treatment observed that anterior edentulousness had no impact on OHRQoL. ${ }^{27}$ However, the participants in the latter study were older (mean age $67.5 \pm 11$ years) and may have less concern about losing their anterior teeth which may explain this finding. With respect to sex of patients, women have been shown to have more concern about their psychological health, social comforts and disabilities, this observation was consistent with the findings in this study. ${ }^{13}$ The mean baseline score for females $(12.6 \pm 12.3)$ was relatively higher than that for males $(9.9 \pm 10.6)$ in this study.

The use of RPDs has been associated with improvement in OHRQoL. ${ }^{13,28}$ The severity of impairment on OHRQoL in this group of patients also lessened after use of both types of dentures. Similar findings were seen by Montero et al., in a group of Spanish patients requiring prosthetic treatment, whose mean OHIP scores decreased from $18.8 \pm 12.7$ (baseline) to $1.9 \pm 3.9$ (after use of acrylic partial denture). ${ }^{13}$ Likewise, in a study comparing acrylic and flexible partial dentures as provisional prosthesis, the median baseline OHIP score of participants dropped from 14.0 to 0.0 after the use of a flexible partial denture. $^{29}$

The improvement in OHRQoL with use of prosthesis may be due to improved diet, aesthetics and social relations. ${ }^{27}$ Also, provision of RPDs has been reported to improve OHRQoL particularly when anterior teeth are replaced and may be more pronounced with the flexible partial denture because of its more aesthetic appearance. Hence, thermoplastic materials should be considered as an alternative RPD base material in treatment planning.
However, the participants in this study were recruited and reviewed over an eight-month period, there is need for further studies on these denture base materials to observe long term clinical outcomes in a larger population of patients. Additionally, dearth of studies on OHRQoL of patients using acrylic and flexible partial dentures limited comparison of this study with others.

\section{CONCLUSION}

In conclusion, at baseline, the OHIP dimension most affected was psychological discomfort. Prosthetic tooth replacement was seen to have an impact on OHRQoL of the participants. There was improvement in the OHRQoL of the participants after using the acrylic and flexible partial dentures, but more so for the flexible partial dentures.

\section{REFERENCES}

1. Arafa K. Evaluating the physical properties between flexible, cold cured, and heat cured acrylic resin (an invitro study). Life Sci J 2012;9:1707-1710.

2. Allen F. Factors influencing the provision of removable partial dentures by dentists in Ireland. JIr Dent Assoc 2010;56:224-229.

3. Ogunrinde TJ, Ajayi DM, Dosumu OO. Causes and pattern of fracture of acrylic dentures among patients seen in a Nigerian teaching hospital. African J Med Med Sci2007;36:365-369.

4. Nejatian T, Johnson A, Noort R. Reinforcement of denture base resin. Adv Sci Technol 2006;49:124129.

5. American Dental Association. Specification no 12, denture base resin material, 1999. Available: http://ebusiness.ada.org/productcatalog/product.aspx?10=696. [Accessed 10 March 2013].

6. Azodo CC, Akinboboye B. Removable partial denture use among a selected group of Nigerian undergraduates. Eur J Gen Dent 2012;1:30-33.

7. Yunus N, Rashid AA, Azmi LL, Abu Hassan MI. Some flexural properties of a nylon denture based polymer. J Oral Rehabil 2005;32:65-71.

8. Kaplan P. Flexible partial denture variations: the use of circumferential, combination and continuous clasp design. Dent today 2012;31:138-141.

9. Budtz-Jorgensen E, Bochet G. Alternate framework designs for removable partial dentures. $J$ Prosthet Dent 1998;80:58-66.

10. Zlataric DK, Celebic A. Treatment outcomes with removable partial dentures: a comparison between patient and prosthodontist assessment. Int J Prosthodont 2001;14:423-426.

11. Stephens RJ, Hopwood P, Girling DJ, Machin D. Randomised trial with quality of life endpoints: are doctors' ratings of patients' physical symptoms 
interchangeable with patients' self ratings? Qual life Res 1997;6:225-236.

12. McGrath C, Bedi R. The importance of oral health to older people's quality of life. Gerodontology 1999;16:59-63.

13. Montero J, Castillo-Oyagu R, Lynch CD, Albaladejo A, Castan A. Self-perceived changes in oral health related quality of life after receiving different types of conventional prosthetic treatments: a cohort follow up study. J Dent 2013;41:493-503.

14. Marcus SE, Drury T, Brown LJ, Zion GR. Tooth retention and tooth loss in the permanent dentition of adults: United States 1988-1991. J Dent Res 1996;75:684-695.

15. Montero J, López J, Vicente M, Galindo M. Comparative validity of the OIDP and OHIP-14 in describing the impact of oral health on quality of life in a cross-sectional study performed in Spanish adults. Med Oral Patol Cir Bucal 2011;16:816-821.

16. Croxford L. ESRC research project on education and youth transitions in England, Wales and Scotland 1984-2002 working paper 4, construction of social class variables. 2002:1-8.

17. Lawal FB, Taiwo JO, Arowojolu MO. How valid are the psychometric properties of the oral health impact profile-14 measure in adult dental patients in Ibadan, Nigeria? Ethiop J Heal Sci2014;24:235-246.

18. Okunseri C, Chattopadhyay A, Lugo RI, Mcgrath C. Pilot survey of oral health related quality of life: a cross-sectional study of adults in Benin City, Edo State, Nigeria. BMC Oral Health 2005;5:7. Doi.10.1186/1472-6831-5-7. Available:http://www.biomedcentral.com/1472-6831/5/7

19. Gerritsen AE, Allen PF, Witter DJ, Bronkhorst EM, Creugers NHJ. Tooth loss and oral health related quality of life: a systematic review and meta-analysis. Health Qual Life Outcomes [Internet]. 2010;8(1):126.

Available: http://www.hqlo.com/content/8/1/126.

20. Esan TA, Olusile AO, Akeredolu PA, Esan AO. Socio-demographic factors and edentulism: the Nigerian experience. BMC Oral Health 2004;6:2-7
[Internet] 2004 [accessed: 16 June 2013]. Available: http://www.biomedcentral.com/1472-6831/4/3.

21. Ehikhamenor EE, Oboro HO, Onuora OI, Umanah AU, Chukwumah NM. Types of removable prostheses requested by patients who presented to the University of Benin teaching hospital dental clinic. $J$ Dent Oral Hyg 2010;2:15-18.

22. Sadiq WM, Idowu AT. Removable partial denture design: a study of a selected population in Saudi Arabia. J Contemp Dent Pr 2002;3:40-53.

23. Taiwo JO, Omokhiodion F. Pattern of tooth loss in an elderly population. Gerodontology 2006;23:117122.

24. Papagiannopoulou V, Oulis CJ, Papaioannou W, Antonogeorgos G, Yfantopoulos J. Validation of a Greek version of the oral health impact profile (OHIP-14) for use among adults. Health Qual Life Outcomes [Internet]. BioMed Central Ltd; 2012;10:7. Available: http://www.hqlo.com/content/10/1/7.

25. Murariu A, Hanganu C. Oral health and quality of life among 45 to 64 year old patients attending a clinic in Iasi, Romania. OHDMBSC 2009;8:7-11.

26. Walter MH, Woronuk JI, Tan H, Lenz U, Koch R, Boening KW,et al. Association with socio-demographic and clinical findings in 3 northern outreach clinics. JCDA 2007;73:153e. Available: http://www.cda-adc.ca/jcda.

27. Motallebnejad M, Hadian H, Mehdizadeh S, Hajiahmadi M. Validity and reliability of the Persian version of the oral health impact profile (OHIP)-14. Casp J Intern Med 2011;2:314-320.

28. Preshaw PM, Walls AWG, Jakubovics NS, Moynihan PJ, Jepson NJA, Loewy Z. Association of removable partial denture use with oral and systemic health. J Dent [Internet]. Elsevier Ltd; 2011;39:711719 . Available: http://dx.doi.org/10.1016/j.jdent.2011.08.018.

29. Roggendorf HC, Dasch W, Baumann MA, Roggendorf MJ. Self-estimated quality of life in wearing two different provisional dentures. Available: http//www.protecdental.com. Accessed: 14 July 2015.

Copyright $($ ) The Author(s). This is an Open Access article under the CC BY license. 